\title{
COMPARISON OF DIFFUSION MODELS FOR DESCRIPTION OF OSMOTIC DEHYDRATION OF RADISH SLICES DIPPED IN BRINE
}

Doi:http://dx.doi.org/10.1590/1809-4430-Eng.Agric.v35n5p894-904/2015

\section{WILTON P. DA SILVA ${ }^{1}$, CLEIDE M. D. P. DA S. E SILVA ${ }^{2}$, JOSIVANDA P. GOMES ${ }^{3}$}

\begin{abstract}
This paper aims at describing the osmotic dehydration of radish cut into cylindrical pieces, using one- and two-dimensional analytical solutions of diffusion equation with boundary conditions of the first and third kind. These solutions were coupled with an optimizer to determine the process parameters, using experimental data. Three models were proposed to describe the osmotic dehydration of radish slices in brine at low temperature. The two-dimensional model with boundary condition of the third kind well described the kinetics of mass transfers, and it enabled prediction of moisture and solid distributions at any given time.
\end{abstract}

KEYWORDS: inverse method; analytical models; cylindrical geometry

\section{COMPARAÇÃO DE MODELOS DE DIFUSÃO NA DESCRIÇÃO DA DESIDRATAÇÃO OSMÓTICA DE FATIAS DE RABANETE EM SALMOURA}

RESUMO: Este artigo descreve a desidratação osmótica de rabanete cortado em pedaços cilíndricos, usando soluções analíticas uni e bidimensionais da equação de difusão com condições de contorno do primeiro e terceiro tipos. Para determinar os parâmetros de processo, tais soluções foram acopladas a um otimizador que usa dados experimentais e o método inverso. Três modelos foram analisados na descrição de um experimento de desidratação osmótica de fatias de rabanete mergulhadas em salmoura, em baixa temperatura. Um modelo bidimensional com condição de contorno do terceiro tipo descreveu bem os processos de migração de massa e possibilitou prever as distribuições de umidade e de sólidos em um instante qualquer.

PALAVRAS-CHAVE: Método inverso, modelos analíticos, geometria cilíndrica.

\section{INTRODUCTION}

Radish (Raphanus sativus L.) is a popular edible root being processed into a range of fresh, dried, salted and pickled products. Even though this vegetable is consumed worldwide, Asia has been the main market. According to COOGAN and WILLS (2002), in Japan, for example, the population consumes radish daily. As for humans, its nutritional value includes carbohydrates, sugars, fibers, fat and protein, aside from vitamins B1-B6, B9 and C and calcium, iron and magnesium, among others. This way, several studies on radish are found in the literature because of such nutritional importance (COOGAN and WILLS, 2002; HERMAN-LARA et al., 2013; GOYENECHE et al., 2013), and some of these researches will be highlighted hereinafter.

After harvest, deteriorating changes of farm products are influenced, in some way or other, by internal water concentration and mobility. Thus, it is known that shelf life increases with water removal. As reported by DA SILVA et al. (2014) and many other authors, the use of hot air to remove water from plant tissues consists of an expensive process owning to liquid-vapor phase change phenomenon, once latent heat of vaporization is high. As a result, pretreatments are generally applied before convective drying. For instance, osmotic dehydration is a simple and inexpensive method of water partial removal during vegetable drying (Da SILVA et al., 2013). In

\footnotetext{
${ }^{1}$ Eng $^{\circ}$ Eletricista, Prof. Doutor, Departamento de Física, UFCG/Campina Grande - PB, Fone: (83) 2101-1044, wiltonps@uol.com.br.

${ }^{2}$ Licenciada em Física, Prof. Doutor, Departamento de Física, UFCG/Campina Grande - PB, cleidedps@ gmail.com.

${ }^{3}$ Eng $^{\circ}$ Agrícola, Prof. Doutor, Departamento de Engenharia Agrícola, UFCG/Campina Grande - PB, josivanda@gmail.com.

Recebido pelo Conselho Editorial em: 19-7-2013

Aprovado pelo Conselho Editorial em: 4-5-2015
} 
this sense, HERMAN-LARA et al. (2013) investigated equilibrium and dynamic mass transfer properties of water and solute during osmotic dehydration of radish slices dipped in sodium chloride solutions at varied concentrations and temperatures. Then, these authors used one-dimensional analytical model for mass transfer based on Fick's second law to describe water loss and solute gain curves. According to these authors, their results may be applied to determine a set of conditions (process time, brine concentration and process temperature) yielding an osmodehydrated radish product within given specifications. The diffusion model used by HERMAN-LARA et al. (2013) to describe the mass transfers within the cylindrical pieces of radish involves, mainly, two simplifications: (1) the slices were considered as infinite slabs; (2) the boundary condition of diffusion equation is of first order. As an advantage, this model can determine mass diffusivities by means of simple regressions. However, SILVA et al. (2013), studying drying of banana slices, noted that external resistance to water flow and the real product geometry should not be neglected prior to analysis of their influence on process description. Therefore, studies aiming to eliminate simplifications 1 and 2 may provide better results for description of radish osmotic dehydration.

This paper has as main goal to describe mass transfers in radish slices during osmotic dehydration, using three different diffusion models, including process optimization and simulation. The models used were one- and two-dimensional analytical solutions of diffusion equation with boundary conditions of first and third order. Process parameters for each model can be thus obtained by using the experimental dataset and further determining the corresponding statistical indicators. Therefore, mass transfer kinetics can be simulated and analyzed for the best model.

\section{MATERIAL AND METHODS}

During osmotic dehydration of radish (Raphanus sativus L.) cut into cylindrical pieces, mass transfers within slices can be considered as diffusion phenomenon. Thus, an analytical solution of diffusion equation can be used to describe these transfers. On the other hand, a finite cylinder of radius $R$ and height $L$ can be interpreted as intersection point of infinite slab of thickness $L$ and infinite cylinder of radius $R$, as is shown in Fig. 1.

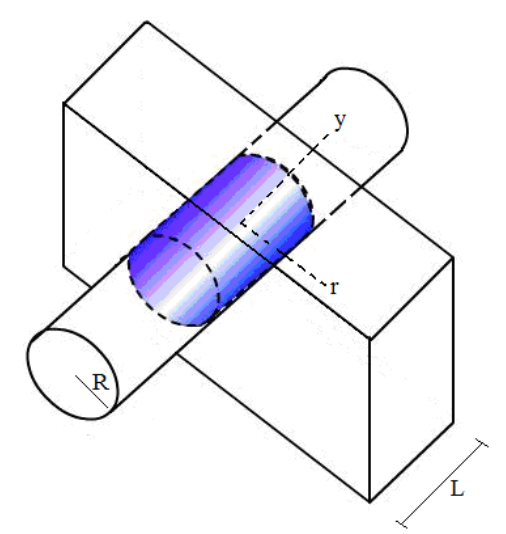

FIGURE 1. Finite cylinder of height $L$ (y-axis) and radius $R$ (r-axis) obtained by intersecting an infinite slab (thickness $L$ ) with an infinite cylinder (radius $R$ ).

As observed by LUIKOV (1968), if a symmetric diffusion in relation to the y-axis is assumed, a position can be given by the coordinates $(r, y)$ defined through the system of axes $r$ and y with origin at the center of the finite cylinder (Fig. 1).

To describe mass transfers during osmotic dehydration of cylindrical pieces of radish, we raised a few presumptions as (1) product dimensions do not vary with mass transfer; (2) moisture and solid initial distributions are uniform; (3) diffusion is the only transport mechanism inside the cylinder; (4) the cylinder is considered homogeneous and isotropic; (5) the effective mass diffusivities for water and solid do not vary during osmotic dehydration; (6) the convective mass transfer coefficients for water and solid are constant; (7) the diffusion of water and solid can be considered independent of each other. 
Three diffusion models are described below. These models represent the mass transfers occurred in cylindrical slices of radish throughout the osmotic dehydration.

\section{Model 1: Finite cylinder with convective boundary condition}

As stated by DA SILVA et al. (2012) and SILVA et al. (2013), the analytical solution of diffusion equation in cylindrical coordinates under the above-mentioned assumptions can be obtained by separation of variables and results in:

$$
\begin{aligned}
& X(r, y, t)=X_{e q}+\left(X_{0}-X_{e q}\right) \sum_{n=1}^{\infty} \sum_{m=1}^{\infty} A_{n, 1} A_{m, 2} J_{0}\left(\mu_{n, 1} \frac{r}{R}\right) \cos \left(\mu_{m, 2} \frac{y}{L / 2}\right) \times \\
& \exp \left[-\left(\frac{\mu_{n, 1}^{2}}{R^{2}}+\frac{\mu_{m, 2}^{2}}{(L / 2)^{2}}\right) D t\right],
\end{aligned}
$$

where,

$X$ represents water loss or solid gain;

$D$ is the effective mass diffusivity;

$t$ is the time, $r$ and $y$ are the coordinates of position;

$X_{e q}$ is the equilibrium value of $X$, and

$X_{0}$ is the initial value of $X$.

The coefficients $A_{n, 1}$ and $A_{m, 2}$ are given by the following equations:

$$
A_{n, 1}=\frac{2 B i_{1}}{J_{0}\left(\mu_{n, 1}\right)\left(B i_{1}^{2}+\mu_{n, 1}^{2}\right)}
$$

and

$$
A_{m, 2}=(-1)^{m+1} \frac{2 B i_{2}\left(B i_{2}^{2}+\mu_{m, 2}^{2}\right)^{1 / 2}}{\mu_{m, 2}\left(B i_{2}^{2}+B i_{2}+\mu_{m, 2}^{2}\right)} .
$$

In eqs. (1) and (2), $J_{0}$ is the Bessel function of first kind of order zero. In eqs. (1) and (3), $\mu_{n, 1}$ and $\mu_{m, 2}$ are, respectively, the roots of the characteristic equations for infinite cylinder and infinite slab. In eqs. (2) and (3), $B i_{1}$ and $B i_{2}$ are the mass transfer Biot numbers relative to both infinite cylinder and slab, respectively. The expressions for these Biot numbers are given as follows:

$$
B i_{1}=\frac{h R}{D}
$$

and

$$
B i_{2}=\frac{h(L / 2)}{D}
$$

where,

$h$ is the convective mass transfer coefficient.

From the comparison between eqs. (4) and (5), the following relationship between $B i_{1}$ and $B i_{2}$ is obtained by the equation:

$$
B i_{2}=\frac{B i_{1}(L / 2)}{R} .
$$


The expressions to determine $\mu_{n, 1}$ and $\mu_{m, 2}$ are given by:

$$
\frac{J_{0}\left(\mu_{n, 1}\right)}{J_{1}\left(\mu_{n, 1}\right)}=\frac{\mu_{n, 1}}{B i_{1}}
$$

and

$$
\cot \mu_{m, 2}=\frac{\mu_{m, 2}}{B i_{2}}
$$

In [eq. (7)], $J_{1}$ is the Bessel function of first kind of first order. Conversely, in experiments of radish osmotic dehydration, only averages of water loss and solid gain will be measured at a given instant $t$. Thus, an expression to determine the average value of $X$ at time $t$, denoted by $\bar{X}(t)$, should be obtained from eq. (1). This expression is obtained through the following equation:

$$
\bar{X}(t)=\frac{1}{V} \int X(r, y, t) d V
$$

where,

$V$ is the finite cylinder volume.

Substituting eq. (1) into eq. (9), it is obtained:

$$
\bar{X}(t)=X_{e q}+\left(X_{0}-X_{e q}\right) \sum_{n=1}^{\infty} \sum_{m=1}^{\infty} B_{n, 1} B_{m, 2} \exp \left[-\left(\frac{\mu_{n, 1}^{2}}{R^{2}}+\frac{\mu_{m, 2}^{2}}{(L / 2)^{2}}\right) D t\right] .
$$

The coefficients $B_{n, 1}$ and $B_{m, 2}$ are given by:

$$
B_{n, 1}=\frac{4 B i_{1}^{2}}{\mu_{n, 1}^{2}\left(B i_{1}^{2}+\mu_{n, 1}^{2}\right)}
$$

and

$$
B_{m, 2}=\frac{2 B i_{2}^{2}}{\mu_{m, 2}^{2}\left(B i_{2}^{2}+B i_{2}+\mu_{m, 2}^{2}\right)} .
$$

To extract values from Eq. (1) and (10), the roots $\mu_{n, 1}$ and $\mu_{m, 2}$ must be known for a given $B i_{1}$ and $B i_{2}$, respectively. Thus, the first 16 roots of [eq. (7)] were calculated for 452 specified values of mass transfer Biot numbers, from $B i_{1}=0$ (which corresponds to an infinite resistance of water flux at the surface) to $B i_{1}=200$ (which practically corresponds to an equilibrium boundary condition). Similarly, the first 16 roots of [eq. (8)] were calculated for 472 specified values of mass transfer Biot numbers, from $B i_{2}=0$ to $B i_{2}=200$.

To determine $D$ and $h$ by optimization, using an experimental dataset, the objective function to be minimized is given by (SILVA et al., 2010):

$$
\chi^{2}=\sum_{i=1}^{N_{p}}\left[\bar{X}_{i}^{\exp }-\bar{X}_{i}^{\text {ana }}\left(D, B i_{1}\right)\right]^{2} \frac{1}{\sigma_{i}^{2}}
$$


in which,

$\bar{X}_{i}^{\text {exp }}$ is the $i^{\text {th }}$ experimental point;

$\bar{X}_{i}^{a n a}\left(D, B i_{1}\right)$ is the analytical average value of $\bar{X}$ at the same point, given as a function of $D$ and $B i_{1}$;

$\sigma_{i}$ is the standard deviation of $\bar{X}_{i}^{\text {exp }}$;

$D$ is the effective mass diffusivity, and

$N_{p}$ is the number of experimental points.

For a specified value of $B i_{1}$ (and consequently $B i_{2}$ ), the chi-square depends only on a single variable, namely the effective mass diffusivity, $D$. Thus, optimum values of $D$ can be determined for each one of the $452 B i_{1}$ defined for the cylinder. The best $D$ is determined by a minimum $\chi^{2}$ among the 452 minima calculated. Each one of the 452 optimization process was accomplished as recommended by SILVA et al. (2009) and SILVA et al. (2010).

In the optimizations, for a stipulated $B i_{1}, B i_{2}$ is calculated by [eq. (6)], and $\mu_{m, 2}$ corresponding to each $B i_{2}$ was determined by linear interpolation, using previously calculated values. In contrast, once $D$ and $h$ are determined through optimization, [eq. (1)] can be used to determine solid distribution (and water loss) as a function of position $(r, y)$, at time $t$.

\section{Model 2: Infinite slab with convective boundary condition}

To investigate if geometric factor is important to modeling the mass transfers in osmotic dehydration of radish slices, model 2 was defined as an infinite slab with boundary condition of the third kind. Thus, if finite cylinder dimensions satisfy a relationship of $R \gg L$, then [eq. (10)] can be re-written for an infinite slab, in the following way:

$$
\bar{X}(t)=X_{e q}+\left(X_{0}-X_{e q}\right) \sum_{m=1}^{\infty} B_{m, 2} \exp \left(-\frac{\mu_{m, 2}^{2}}{(L / 2)^{2}} D t\right),
$$

where,

$\mu_{m, 2}$ and $B_{m, 2}$ are calculated by eqs. (8) and (12), respectively. Equation (14) together with eqs. (8) and (12) represent the analytical solution of diffusion equation with boundary condition of the third kind for an infinite slab with thickness $L$.

\section{Model 3: Infinite slab with equilibrium boundary condition}

To investigate if the boundary condition is important to modeling the mass transfers in osmotic dehydration of radish slices, model 3 was established as an infinite slab with boundary condition of the first kind. The boundary condition of the first kind means an infinite mass transfer Biot number: $B i_{2} \rightarrow \infty$. Thus, [eq. (8)] becomes:

$$
\cot \mu_{m, 2}=0
$$

and, consequently,

$$
\mu_{m, 2}=\pi(2 m-1) / 2
$$

When, $B i_{2} \rightarrow \infty$, the coefficients $B_{m, 2}$ of [eq. (14)], which are given by [eq. (12)], result in: 


$$
B_{m, 2}=\frac{2}{\mu_{m, 2}^{2}} .
$$

Equation (14) together with eq. (16) and (17) are the analytical solution of diffusion equation with boundary condition of the first kind for an infinite slab with thickness $L$.

\section{Material}

We used the most commonly known variety of radish (Raphanus Sativus L.), red-skinned variety, with a moisture content of $0.95 \mathrm{~g}$ water/ $\mathrm{g}$ wet product, for osmotic dehydration modeling. The vegetables were cut into cylindrical slices with the following average dimensions: thickness $L$ $=5 \mathrm{~mm}$ and radius $R=20 \mathrm{~mm}$. The process was performed using sodium chloride solutions and distilled water, which were prepared at a concentration of $15 \mathrm{~g} \mathrm{NaCl} / 100 \mathrm{~g}$ water. Brine stirring was performed by agitation at $120 \mathrm{rpm}$ with a digital plate stirrer. We used a ratio of 1: 15 between radish slice and brine. This proportion was adopted to ensure osmotic solution concentration steadiness throughout the experiment. Geometry and boundary condition influences on water and sodium chloride transfers were analyzed at $25^{\circ} \mathrm{C}$, that is, close to room temperature. As it is known, moderate temperatures can enhance color and flavor retention (KHIN et al., 2006), as well as providing least thermal degradation of nutrients (JAIN et al., 2011). The experiments were conducted as in HERMAN-LARA et al. (2013), in which water loss and sodium chloride gain were determined by gravimetric method (precision of $0.001 \mathrm{~g}$ ). At each sampling, the slices were rinsed under distilled water and gently wiped with paper towel to remove outer moisture. Thereafter, samples were dried in an oven at $105^{\circ} \mathrm{C}$ for 8 hours, enough time to achieve equilibrium.

The variables of interest to be analyzed in radish slices at a given instant $t$ are water loss $\left(\bar{M}_{(t)}\right)$, and sodium chloride gain $\left(\bar{S}_{(t)}\right)$. Such variables were obtained by the following equations:

$$
\bar{M}(t)=\frac{m_{W}(0)-m_{W}(t)}{m_{0}}
$$

and

$$
\bar{S}(t)=\frac{m_{S}(t)}{m_{0}}
$$

In eq. (18) and (19), $m_{W}(t)$ is the water at any time $t, m_{S}(t)$ is the sodium chloride mass migrated to the slices at any time $t, m_{W}(0)$ is the initial water mass in the sample and $m_{o}$ is the initial mass of the wet sample. First, each sample was weighted, and dry matter was determined from one of them. This procedure enables calculating the initial dry matter of each sample. After that, at each instant $t$, sample mass and dry mass were measured; and this way water loss $\bar{M}(t)$ and sodium chloride gain $\bar{S}(t)$ could be calculated for samples still dipped in brine at instant $t$. Table 1 shows the experimental datasets to be analyzed. 
Table 1. Experimental datasets of water loss and sodium chloride gain throughout time.

\begin{tabular}{ccc}
\hline $\mathrm{t}(\min )$ & $\bar{M}\left(g g^{-1}\right)$ & $\bar{S}\left(g g^{-1}\right)$ \\
\hline 0 & 0.0000 & 0.0000 \\
2 & 0.0555 & 0.0025 \\
4 & 0.0756 & 0.0055 \\
6 & 0.1143 & 0.0080 \\
8 & 0.1429 & 0.0103 \\
10 & 0.1714 & 0.0129 \\
15 & 0.1933 & 0.0149 \\
20 & 0.2235 & 0.0170 \\
25 & 0.2437 & 0.0193 \\
30 & 0.2655 & 0.0213 \\
40 & 0.2891 & 0.0229 \\
50 & 0.3042 & 0.0241 \\
60 & 0.3176 & 0.0249 \\
70 & 0.3227 & 0.0250 \\
80 & 0.3260 & 0.0255 \\
90 & 0.3260 & 0.0255 \\
110 & 0.3260 & 0.0255 \\
\hline
\end{tabular}

When describing water loss over time using the analytical solutions presented here, it is required to change the symbol $X$ in eq. (1), (10), (13) and (14) to $M$. Yet for sodium chloride penetration, the appropriate symbol is $S$, instead of $X$. Moreover, it can be observed that for dataset in Table 1 at instant $\mathrm{t}=0, M_{0}=S_{0}=0, M_{e q}=0.3260$ as well as $S_{e q}=0.0255$.

\section{RESULTS AND DISCUSSION}

Table 2 shows the optimization results for sodium chloride gain and water loss, for each proposed model.

TABLE 2. Optimization results for sodium chloride gain and water loss.

\begin{tabular}{|c|c|c|c|c|c|}
\hline Model & $D\left(\mathrm{~m}^{2} \min ^{-1}\right)$ & $h\left(\mathrm{~m} \min ^{-1}\right)$ & $B i_{2}$ & $\chi^{2}$ & $R^{2}$ \\
\hline & \multicolumn{5}{|c|}{ NaClGain } \\
\hline 1 & $5.177 \times 10^{-7}$ & $1.569 \times 10^{-4}$ & 0.758 & $3.043 \times 10^{-6}$ & 0.9976 \\
\hline 2 & $3.818 \times 10^{-7}$ & $2.214 \times 10^{-4}$ & 1.450 & $3.310 \times 10^{-6}$ & 0.9973 \\
\hline \multirow[t]{2}{*}{3} & $1.147 \times 10^{-7}$ & - & - & $2.170 \times 10^{-5}$ & 0.9904 \\
\hline & \multicolumn{5}{|c|}{ WaterLoss } \\
\hline 1 & $1.832 \times 10^{-7}$ & $2.931 \times 10^{-4}$ & 4.000 & $5.123 \times 10^{-4}$ & 0.9973 \\
\hline 2 & $1.783 \times 10^{-7}$ & $4.815 \times 10^{-4}$ & 6.750 & $5.570 \times 10^{-4}$ & 0.9970 \\
\hline 3 & $1.179 \times 10^{-7}$ & - & - & $1.475 \times 10^{-3}$ & 0.9950 \\
\hline
\end{tabular}

Once process parameters have already been determined for each model, sodium chloride kinetics can be drawn together with experimental dataset, as is shown in Fig. 2. 


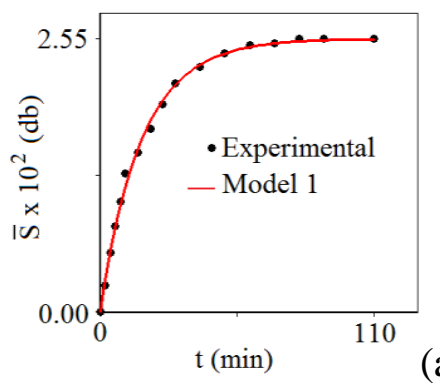

(a)

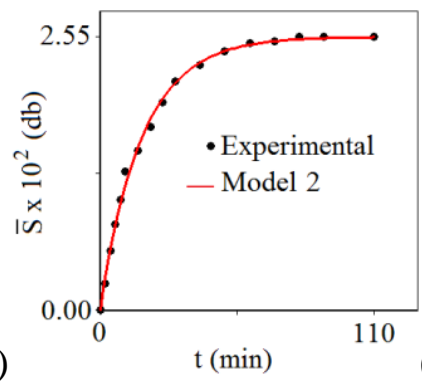

(b)

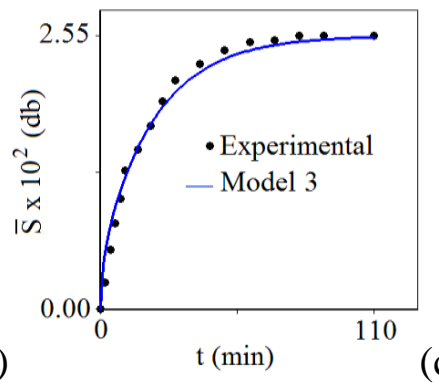

FIGURE 2. Sodium chloride gain kinetics described through: (a) Model 1; (b) Model 2; (c) Model 3.

Fig. 3 shows the simulations of water loss kinetics over time using the three proposed models.
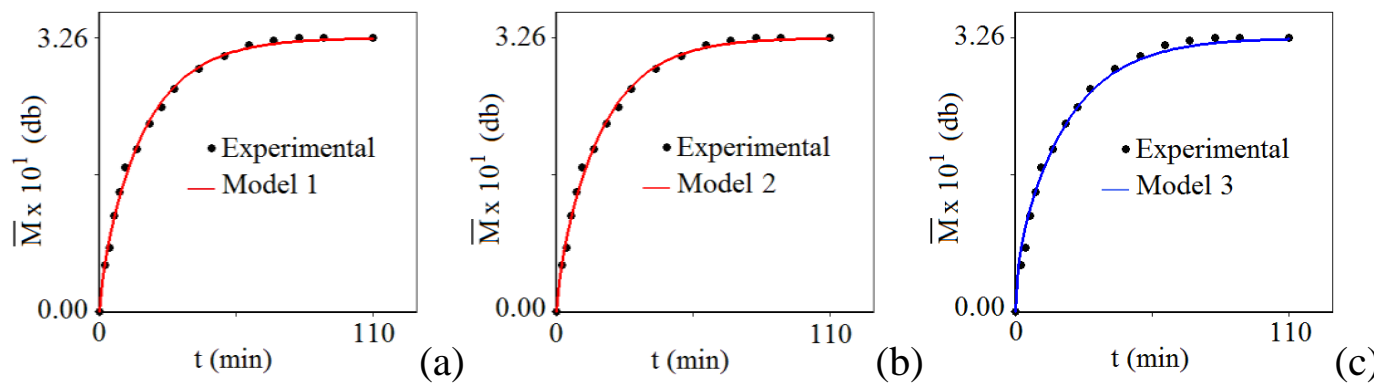

FIGURE 3. Water loss kinetics described through: (a) Model 1; (b) Model 2; (c) Model 3.

Fig. 4 states the distributions of water loss and sodium chloride gain within the cylinder, highlighting the area within the ry-axis where such distributions will be shown using model 1 .

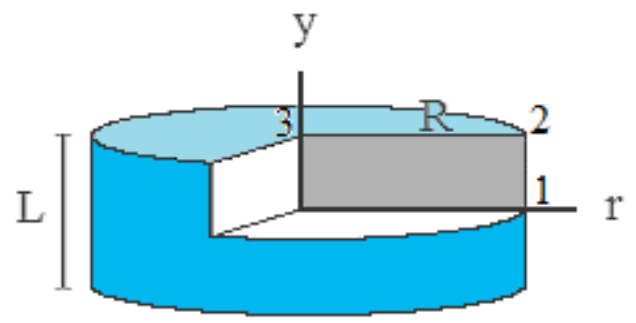

FIGURE 4. Finite cylinder (with no scale) highlighting the area within the ry-axis where water loss and sodium chloride gain distributions will be shown using model 1 .

Fig. 5 indicates the distributions of sodium chloride gain at two different instants $(t=5.5$ and $11.0 \mathrm{~min}$ ), using model 1.
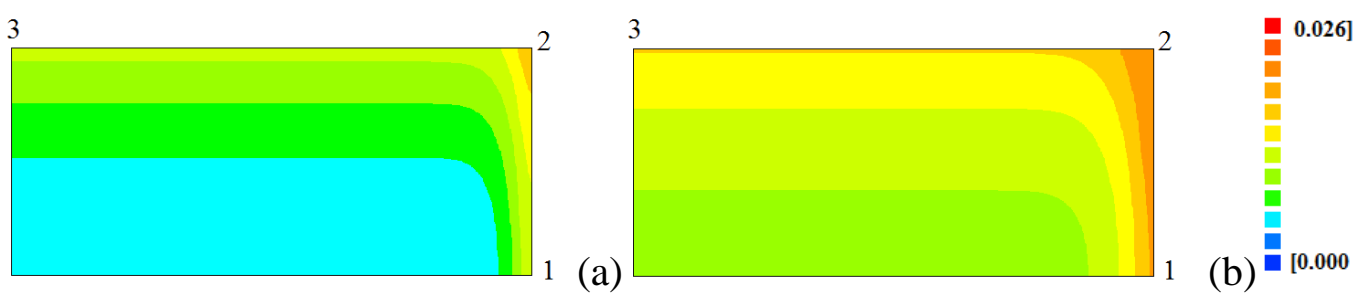

FIGURE 5. Sodium chloride gain distribution (with non-scaled rectangle) at instants: (a) $t=5.5 \mathrm{~min}$; (b) $t=11.0 \mathrm{~min}$.

Fig. 6 shows the distributions of water loss, already presented in Fig. 4, at two different instants $(\mathrm{t}=5.5$ and $11.0 \mathrm{~min})$, using model 1 . 

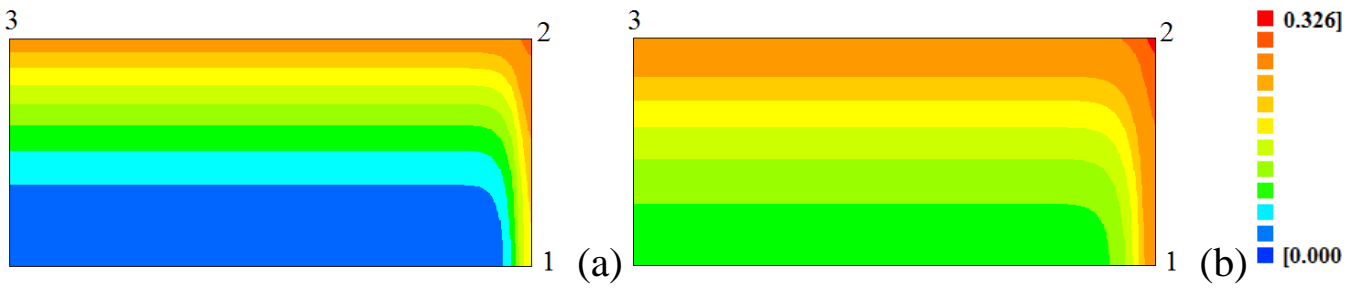

FIGURE 6. Water loss distribution (with non-scaled rectangle) at instants: (a) $t=5.5 \mathrm{~min}$; (b) $t=11.0 \mathrm{~min}$.

Unlike models 1 and 2, in which two process parameters must be determined ( $D$ and $\left.B i_{2}\right)$, model 3 requires a single process parameter $(D)$. In this case, this parameter could be also determined by a simple non-linear regression, using commercial software instead of a specific optimization algorithm. To minimize cut-off errors, we used number of 256 (16 x 16 terms) series terms to represent model 1, which is two-dimensional, while for the one-dimensional models 2 and 3 , it was 16.

In the literature, diffusion models with boundary condition of the first kind are mostly used to explain convective drying (SILVA et al., 2009; DA SILVA et al., 2012; SILVA et al., 2012; DOYMAZ, 2013) and also osmotic dehydration of agricultural products (QUEIROZ et al., 2010; SOUZA SILVA et al., 2011; MERCALI et al., 2011; HERMAN-LARA et al., 2013). Overall, the boundary condition is derived from the agitation condition of the environment within which a particular product is immersed. However, as observed by SILVA et al. (2013), external resistance to mass transfer may not be discarded prior to analysis of its influence on mass transfer processes. In addition, several researches have reported that a simplified product geometry reduces diffusion problem in one-dimensional cases (SINGH et al., 2008). Regarding mass transfers in radish, for instance, model 2 and 3 ignore a radial mass transport, considering only an axial flux.

Concerning sodium chloride, Fig. 2 illustrates that model 3 is very poor when compared with models 1 and 2. Similar result can be seen in Fig. 3 for water transfer. To quantify this observation for sodium chloride data, Tab. 2 shows the chi-square of model 3, which is about 7 times greater than model 1. However, this relationship for water loss is about 3. Thus, even if brine had been stirred, model 3 should be disregarded in a precise description of osmotic dehydration of radish slices, as assessed in this paper. Anyway, according to Table 2, the use of model 3 is less critical to describe water loss $\left(R^{2}=0.9950\right)$ than sodium chloride gain $\left(R^{2}=0.9904\right)$. On the other hand, when comparing statistical indicators of both models, we can conclude that model 1 is superior to model 2 , as is expected. Therefore, the closer the geometry is to real values, the better the results are. Nevertheless, all the results securely indicate the correct choice of a boundary condition as the most significant factor in process description, which must be of the third kind.

The excellence of model 1 in comparison to model 2 points out that maintenance of peel during radish cutting would not prevent mass transfer. Even so, if model 2 is chosen to describe mass transfers, researchers must take into account the overestimation of Biot number, as is shown in Table 2. As observed, $B i_{2}$ changed from 0.758 to 1.450 for sodium chloride case, and from 4.000 to 6.750 for water loss.

As observed in Fig. 6 for sodium chloride and in Fig. 7 for water loss, the osmotic dehydration occurs differently depending on the surface point (points 1, 2 and 3 as shown in Fig. 4) at a given instant. Even though concentrations at points 1 and 3 are very close, they are different that obtained for point 2. Conversely, it is possible to understand through Fig. 6 and 7 that, outside the region defined by the boundary 1-2, moisture level and sodium chloride contents are very similar to those that would be obtained for an infinite slab. Thus, if moisture and sodium chloride distributions are not required in a given study, model 2 is also a useful tool to describe mass transfer kinetics. 
As a final comment, it can be observed that osmotic dehydration kinetics, moisture and solid distributions at any time and predictive mathematical models are useful tools to get information on mass transfer processes, as well as increase the potential use of radish in agro industry.

\section{CONCLUSIONS}

According to the statistical indicators, model 3 (one-dimensional with boundary condition of the first kind) is inadequate and should be avoided to describe mass transfers, in case of accurate results.

Model 2, which is one-dimensional with boundary condition of the third kind, is reasonable and can majorly be used only after analyzing the kinetics of mass transfers.

Model 1, which two-dimensional with boundary condition of the third kind, presents good statistical indicators for the description of mass transfer kinetics. In addition, it enables predicting the mass distributions of water and solids. Thus, in case of accurate descriptions of osmotic dehydration of radish slices, this model should be preferred.

From the results obtained, we can conclude that external resistance to mass fluxes cannot be discarded prior to analysis of its influence on osmotic dehydration process. In contrast, we observed a lower significance of the geometric factor compared to the correct choice of boundary condition.

\section{ACKNOWLEDGMENT}

The first author wants to thank CNPq (Conselho Nacional de Desenvolvimento Científico e Tecnológico) for all support and for his research grant (Process Number 301697/2012-4). We also want to express our gratitude to the reviewers for comments and suggestions.

\section{REFERENCES}

COOGAN, R.C.; WILLS, R.B.H. Effect of drying and salting on the flavour compound of Asian white radish. Food Chemistry, Reading, v.77, n.3, p.305-307, jun. 2002.

DOYMAZ, I. Effect of blanching temperature and dipping time on drying time of broccoli. Food Science and Technology International, Valencia, v.20, n.2, p.149-157, mar. 2013.

GOYENECHE, R.; DI SCALA, K.; ROURA, S. Biochemical characterization and thermal inactivation of polyphenol oxidase from radish (Raphanus sativus var. sativus). LWT - Food Science and Technology, Athens-Clarke County, v.54, n.1, p.57-62, nov. 2013.

HERMAN-LARA, E.; MARTÍNEZ-SÁNCHEZ, C.E.; PACHECO-ANGULO, H.; CARMONAGARCÍA, R.; RUIZ-ESPINOSA, H.; RUIZ-LÓPEZ I.I. Mass transfer modeling of equilibrium and dynamic periods during osmotic dehydration of radish in $\mathrm{NaCl}$ solutions. Food and Bioproducts Processing, Christchurch, v.91, n.3, p.216-224, jul. 2013.

JAIN, S.K.; VERMA, R.C.; MURDIA, L.K.; JAIN, H.K.; SHARMA, G.P. Optimization of process parameters for osmotic dehydration of papaya cubes. Journal of Food Science and Technology, Mysore, v.48, n.2, p211-217, apr. 2011.

KHIN, M.M.; ZHOU, W.; PERERA, C.O. A study of the mass transfer in osmotic dehydration of coated potato cubes. Journal of Food Engineering, Davis, v.77, n.1, p.84-95, nov. 2006.

LUIKOV, A.V. Analytical heat diffusion theory. London: Academic Press, 1968. 685 p.

MERCALI, G.D.; MARCZAK, L.D.F.; TESSARO, I.C.; NOREÑA, C. P.Z. Evaluation of water, sucrose and $\mathrm{NaCl}$ effective diffusivities during osmotic dehydration of banana (Musa sapientum, shum.). LWT - Food Science and Technology, Athens-Clarke County, v.44, n.1, p.82-91, jan. 2011. 
QUEIROZ, V.A.V.; BERBERT, P.A.; MOLINA; M.A.B.; GRAVINA, G.A.; QUEIROZ, L.R. Mecanismos de transferência de massa na desidratação osmótica de goiaba em soluções de sacarose, sucralose e açúcar invertido. Engenharia Agrícola, Jaboticabal, v.30, n.4, p.715-725, jul./aug. 2010.

SILVA C.M.D.P.S.; SILVA W.P. da; FARIAS V.S.O.; GOMES J.P. Effective diffusivity and convective mass transfer coefficient during the drying of bananas. Engenharia Agrícola, Jaboticabal, v.32, n.2, p.342-353, mar./apr. 2012.

SILVA, W.P. da; SILVA, C.M.D.P.S.; GOMES, J.P. Comparison of boundary conditions to describe drying of turmeric (Curcuma longa) rhizomes using diffusion models. Journal of Food Science and Technology, Mysore, v.51, n.1, p.3181-3189, nov. 2012.

SILVA, W.P. da; AMARAL, D.S.; DUARTE, M.E.M.; MATA, M.E.R.M.C.; SILVA, C.M.D.P.S.; PINHEIRO, R.M.M.; PESSOA, T. Description of the osmotic dehydration and convective drying of coconut (Cocos nucifera L.) pieces: A three-dimensional approach. Journal of Food Engineering, Davis, v.115, n.1, p.121-131, mar. 2013.

SILVA, W.P. da; PRECKER, J.W.; SILVA, C.M.D.P.S.; GOMES, J.P. Determination of effective diffusivity and convective mass transfer coefficient for cylindrical solids via analytical solution and inverse method: application to the drying of rough rice. Journal of Food Engineering, Davis, v.98, n.3, p.302-308, jun. 2010.

SILVA, W.P.; PRECKER, J.W.; SILVA, C.M.D.P.S.; SILVA, D.D.P.S. Determination of the effective diffusivity via minimization of the objective function by scanning: Application to drying of cowpea. Journal of Food Engineering, Davis, v.95, n.2, p.298-304, nov. 2009.

SILVA, W.P.; SILVA, C.M.D.P.S.; GOMES, J.P. Drying description of cylindrical pieces of bananas in different temperatures using diffusion models. Journal of Food Engineering, Davis, v.117, n.3, p.417-424, aug. 2013.

SILVA, W.P. da; SILVA, C.M.D.P.S.; AIRES, J.E.F.; SILVA JÚNIOR, A.F. Osmotic dehydration and convective drying of coconut slices: Experimental determination and description using onedimensional diffusion model. Journal of the Saudi Society of Agricultural Sciences, Riyadh, v.13, n.2, p.162-168, jun. 2014.

SINGH, B.; PANESAR, P.S.; NANDA, V. Osmotic dehydration kinetics of carrot cubes in sodium chloride solution. International Journal of Food Science and Technology, Christchurch, v.43, n.8, p.1361-1370, aug. 2008.

SOUZA SILVA, K.; CAETANO, L.C.; GARCIA, C.C.; ROMERO, J.T.; SANTOS, A.B.; MAURO, M.A. Osmotic dehydration process for low temperature blanched pumpkin. Journal of Food Engineering, Davis, v.105, n.1, p.56-64, jul. 2011. 